\title{
Study of Flow-Assisted Corrosion of AZ91D Magnesium Alloy in Loop System Based on Array Electrode Technology
}

\author{
Hualiang Huang, ${ }^{1,2}$ Guoan Zhang, ${ }^{1}$ Jiakuan Yang, ${ }^{1}$ Zhiquan Pan, $^{2}$ and Xingpeng Guo' \\ ${ }^{1}$ Hubei Key Laboratory of Materials Chemistry and Service Failure, School of Chemistry and Chemical Engineering, \\ Huazhong University of Science and Technology, Wuhan 430074, China \\ ${ }^{2}$ School of Chemistry and Environmental Engineering, Wuhan Institute of Technology, Wuhan 430073, China
}

Correspondence should be addressed to Hualiang Huang; hhl0425@aliyun.com and Xingpeng Guo; guoxp@mail.hust.edu.cn

Received 10 July 2014; Accepted 12 October 2014

Academic Editor: Guang-Ling Song

Copyright (C) 2015 Hualiang Huang et al. This is an open access article distributed under the Creative Commons Attribution License, which permits unrestricted use, distribution, and reproduction in any medium, provided the original work is properly cited.

\begin{abstract}
A loop system was used to investigate flow-assisted corrosion (FAC) of AZ91D magnesium alloy at an elbow based on array electrode technology by potentiodynamic polarization, computational fluid dynamics, simulation and surface analysis. The experimental results demonstrate the fluid hydrodynamics plays a significant role in the FAC of AZ91D magnesium alloy. The corrosion rate increases from the outer wall to the inner wall of the elbow, with the higher corrosion rate corresponding to the higher flow velocity and larger shear stress at the elbow. The maximum corrosion rate appears at the innermost wall of the elbow, the location with the maximum flow velocity and shear stress.
\end{abstract}

\section{Introduction}

Magnesium alloys appear to be promising alternatives to aluminum alloys and steel used in the automotive industry because of their light density, high strength-to-weight ratio, and good mechanical properties $[1,2]$, especially in the cooling system of an engine block. However, the corrosion of magnesium alloys is a serious problem in the cooling system of an engine block [3], which restricts their applications. During the past decade, there were many research works which focused on the corrosion behaviour and mechanism of magnesium alloys [4-11].

AZ91D magnesium alloy is one of the most popular magnesium alloys used today. Although many works have been done to investigate its corrosion behaviour and mechanism in a static medium [12], there is no report about its corrosion behaviour and mechanism in a flow medium. Since the fluid flow has significant effects on the mass transfer process and the removal of corrosion products on the electrode surface [13], the different corrosion behaviour of AZ91D magnesium alloy is expected in a flow medium.

Flow-assisted corrosion (FAC), caused by the combined action of corrosion and fluid flow, is one of the main reasons resulting in failure of heat exchanger [14]. At present, rotating disk electrode (RDE) or rotating cylinder electrode (RCE) [15-17], impingement jet systems [18-24], and loop systems $[13,25,26]$ have been used extensively for FAC investigation. However, RDE, RCE, and impingement jet systems could not really reflect the flow pattern of fluid in a pipe, especially at an elbow. Therefore, a loop system should be applied to simulate the realistic flow environments in a pipe.

Elbow is an important part of heat exchanger configuration. However, the flow pattern will occur to great changes in flow direction and flow velocity in a $90^{\circ}$ elbow, resulting in significant difference in the corrosion behaviour at different locations of the elbow [27]. Due to the sudden change in the flow pattern, the wall thinning is further exacerbated by FAC at the elbow. Therefore, FAC at the elbow is rather serious among the damage of heat exchanger. Apparently, there should be correlation between the corrosion behaviour at different locations of the elbow and the flow pattern. However, there have been few works to study the different corrosion behaviour at different locations of an elbow [13]. Array electrode technique, a configuration of multielectrode system, can be used for studying the different corrosion behaviour at different locations of the elbow. 


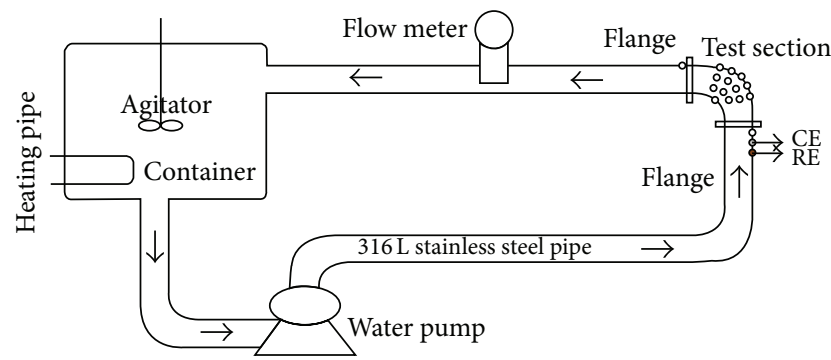

(a)

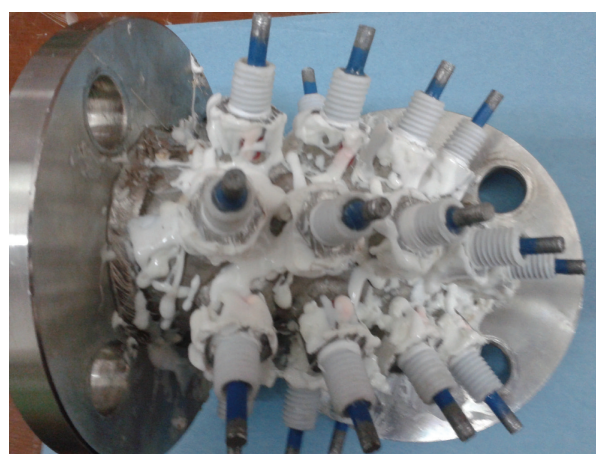

(c)

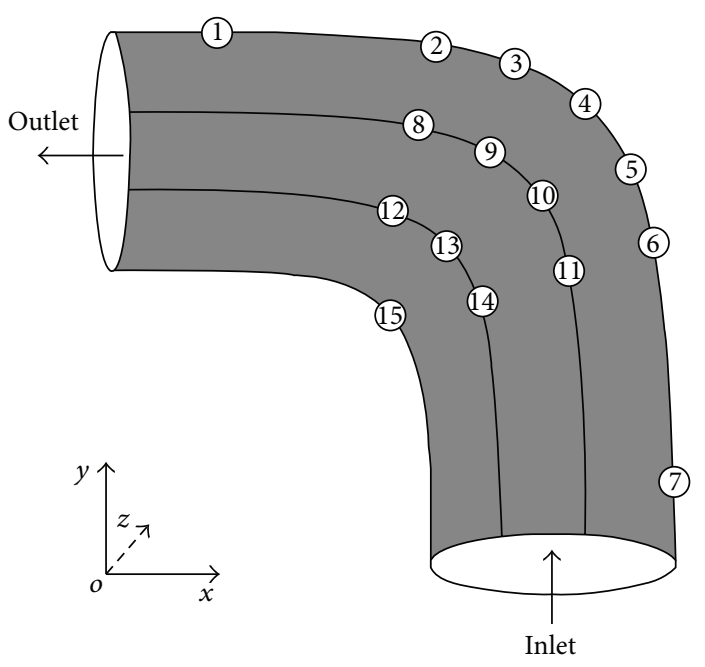

(b)

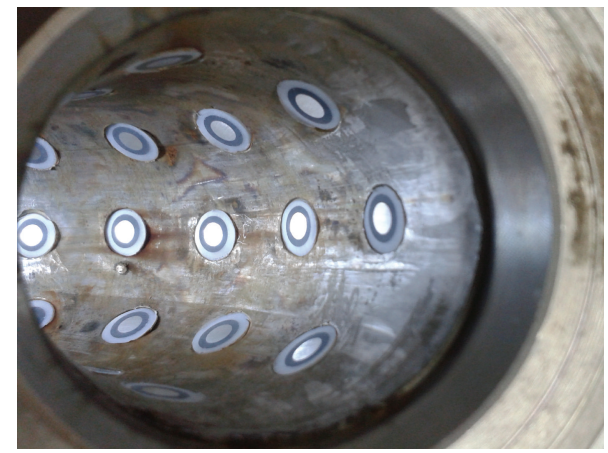

(d)

FIGURE 1: Schematic diagram of FAC loop test system and array electrodes: (a) loop test system, (b) distribution of array electrodes in test section, (c) the assembly of elbow test section, and (d) distribution of array electrodes at the inner wall of elbow.

Based on array electrode technology, a loop system was designed and used to investigate the FAC of AZ91D magnesium alloy at a $90^{\circ}$ elbow in circulating ASTM D138487 solution by potentiodynamic polarization, computational fluid dynamics (CFD) simulation, and surface analysis in this work. The corrosion behaviour and mechanism at different locations of the elbow were investigated to determine the effect of fluid hydrodynamics and the correlation between the corrosion behaviour and the distributions of flow velocity and shear stress at a $90^{\circ}$ elbow.

\section{Experimental}

2.1. Loop System for FAC Test. Figure 1(a) shows the circulating loop system used for FAC test. It consisted of pipes, a centrifugal pump, a container, a pressure gage, a flow meter, and array electrode test section. The solution was supplied from a 125L container and circulated through the centrifugal pump. The flow velocity was controlled by controlling the pump rotational speed using a controller. The flow velocity in this study is $5.31 \mathrm{~m} / \mathrm{s}$, which was measured by the flow meter. The loop system was made of 316L stainless steel pipe with the inner diameter of $50 \mathrm{~mm}$. After pretreatment, array electrodes were mounted into the elbow test section with the same spacing distance in flow direction. Figure 1(b) shows the schematic diagram of the test section. Figure 1(c) shows the photograph of the test section with 20 specimens at the elbow. The exposed surfaces of array electrodes were in accordance with the internal surface of pipe, as shown in Figure 1(d). The 20 specimens at the elbow are symmetrical with respect to the central plane of pipe. In addition, a specimen (electrode 1) is in the straight pipe before the outlet of the elbow, and one specimen (electrode 7) is in the straight pipe after the inlet of the elbow.

2.2. Electrode and Solutions. The array electrodes were made up of AZ91D magnesium alloy with identical diameter of $5 \mathrm{~mm}$ (surface area of $19.625 \mathrm{~mm}^{2}$ ) and height of $60 \mathrm{~mm}$. The specimens were embedded in epoxy resin, leaving a working area of $19.625 \mathrm{~mm}^{2}$. The working surface was polished with 1200 grit emery papers and then cleaned by distilled water and pure ethanol.

The test solution is ASTM D1384-87 solution containing $148 \mathrm{mg} / \mathrm{L}(1.04 \mathrm{mM}) \mathrm{Na}_{2} \mathrm{SO}_{4}+138 \mathrm{mg} / \mathrm{L}(1.64 \mathrm{mM})$ $\mathrm{NaHCO}_{3}+165 \mathrm{mg} / \mathrm{L}(2.82 \mathrm{mM}) \mathrm{NaCl}$, which was made up 


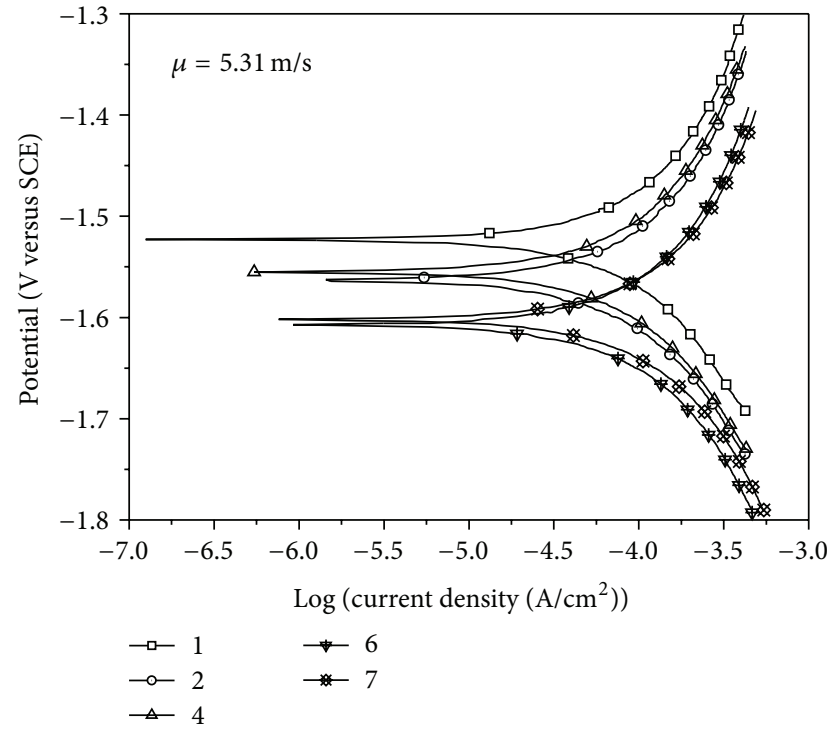

(a)



(b)



(c)

FIgURE 2: Potentiodynamic polarization curves of array electrodes under fluid flow condition with the flow velocity of $5.31 \mathrm{~m} / \mathrm{s}$.

from analytical grade reagents and deionized water. The $\mathrm{pH}$ of the solution is 8.2.

2.3. Potentiodynamic Polarization Measurements. An electrochemical test system was used for potentiodynamic polarization curve measurement during the FAC test. A threeelectrode electrochemical cell was constructed with array electrodes as working electrodes (WE), a platinum plate as counter electrode (CE), and a saturated calomel electrode (SCE) as reference electrode (RE), and CE and RE were located at the straight pipe before the inlet of the elbow and closer to the array electrodes, as shown in Figure 1(a). Potentiodynamic polarization curve was measured at a potential sweep rate of $1 \mathrm{mV} / \mathrm{s}$ after the working electrode had reached a steady state in the solution [28]. For the reproducibility, the polarization curve measurements were repeated more than three times. The test was performed with the flow velocity of $5.31 \mathrm{~m} / \mathrm{s}$ at room temperature (about $25^{\circ} \mathrm{C}$ ) and an atmospheric pressure.

2.4. Surface Morphology Analysis after FAC Test. After FAC test, the surface morphologies of array electrodes were observed by an optical microscope (VHX-1000E, Keyence, Japan).

2.5. CFD Simulation. Professional fluid simulation software Fluent was employed to perform CFD simulation. Preprocessing software Gambit was used to establish the geometric model. The straight section before the inlet of the elbow was set as $0.5 \mathrm{~m}$ and the straight section before the outlet of 




FIGURE 3: Distribution of corrosion current densities of array electrodes at test section under fluid flow condition with the flow velocity of $5.31 \mathrm{~m} / \mathrm{s}$ (unit: $\mu \mathrm{A} / \mathrm{cm}^{2}$ ).

the elbow was also set as $0.5 \mathrm{~m}$. Volume meshes were constructed with the interval size of $0.01 \mathrm{~m}$. A flow velocity of $5.31 \mathrm{~m} / \mathrm{s}$ at the inlet and an atmospheric pressure (101325 Pa) at the outlet were set as the boundary conditions. The fluid was assumed to be incompressible and a $k-\varepsilon$ turbulent model (double equation model) was used to numerically solve the simulation since the fluid flowed at a Reynolds number of 265500 (calculated according to the inner diameter of pipe and flow velocity). The Reynolds number was much higher than 4000 , indicating a turbulent flow. Turbulence intensity in the simulation was $3.36 \%$ (calculated according to the calculated Reynolds number). The $k-\varepsilon$ turbulence equation was solved by iterative method with a convergence criterion of 0.00001 .

\section{Results}

3.1. Potentiodynamic Polarization Curve Measurement. Potentiodynamic polarization curves of AZ91D magnesium alloy array electrodes under the flow condition with $5.31 \mathrm{~m} / \mathrm{s}$ are shown in Figure 2. It is seen from Figure 2 that these electrodes are in an active dissolution state under the flow condition, and the polarization curves of all the specimens exhibit the similar shape. The polarization curves can be analyzed through cathodic Tafel extrapolation [28]. The electrochemical parameters, including corrosion potential $\left(E_{\text {corr }}\right)$, corrosion current density $\left(I_{\text {corr }}\right)$, and cathodic Tafel slope $\left(b_{c}\right)$, are fitted and listed in Table 1 . Figure 3 shows the distribution of corrosion current densities of array electrodes at the elbow. According to Figure 3, the corrosion current density increases from the outer wall to the inner wall of the elbow, and the maximum corrosion current density appears at the innermost side of the elbow. At the outermost side of the elbow, the corrosion current density decreases at first and then increases along the direction of fluid flow. However, the
TABLE 1: The fitting parameters of polarization curves of array electrodes under fluid flow condition with the flow velocity of $5.31 \mathrm{~m} / \mathrm{s}$.

\begin{tabular}{lccc}
\hline $\begin{array}{l}\mathrm{E} \\
(\text { electrode })\end{array}$ & $\begin{array}{c}E_{\text {corr }} \\
(\mathrm{mV}(\mathrm{SCE}))\end{array}$ & $\begin{array}{c}B_{c} \\
(\mathrm{mV} / \text { decade })\end{array}$ & $\begin{array}{c}\text { Corrosion } \\
\text { current density } \\
\left(\mathrm{A} / \mathrm{cm}^{2}\right)\end{array}$ \\
\hline 1 & -1524 & -255.7 & $9.02 \times 10^{-5}$ \\
2 & -1562 & -245.7 & $8.66 \times 10^{-5}$ \\
3 & -1551 & -259.2 & $9.17 \times 10^{-5}$ \\
4 & -1555 & -260.8 & $9.17 \times 10^{-5}$ \\
5 & -1572 & -253.9 & $9.38 \times 10^{-5}$ \\
6 & -1607 & -258.7 & $9.94 \times 10^{-5}$ \\
7 & -1603 & -274.4 & $1.22 \times 10^{-4}$ \\
8 & -1531 & -277.4 & $9.63 \times 10^{-5}$ \\
9 & -1521 & -281.2 & $9.78 \times 10^{-5}$ \\
10 & -1566 & -273.6 & $9.89 \times 10^{-5}$ \\
11 & -1564 & -273.3 & $9.99 \times 10^{-5}$ \\
12 & -1543 & -265.9 & $1.00 \times 10^{-4}$ \\
13 & -1542 & -265.9 & $1.01 \times 10^{-4}$ \\
14 & -1556 & -259.8 & $1.05 \times 10^{-4}$ \\
15 & -1537 & -278.0 & $1.15 \times 10^{-4}$ \\
\hline
\end{tabular}

corrosion current density gradually increases from electrode 8 to electrode 11 and from electrode 12 to electrode 14 along the direction of fluid flow, which indicates the corrosion rate gradually increases from electrode 8 to electrode 11 and from electrode 12 to electrode 14 along the direction of fluid flow, respectively.

3.2. CFD Simulation. Figure 4 shows the three-dimensional distributions of fluid flow velocity and shear stress at the elbow with a flow velocity of $5.31 \mathrm{~m} / \mathrm{s}$. Three-dimensional distributions of fluid flow velocity and shear stress along the elbow are symmetrical with respect to the central plane of pipe. From the distribution of fluid flow velocity at the elbow (Figure 4(a)), flow velocity decreases from the innermost side to the outermost side, with the highest flow velocity about $6.88 \mathrm{~m} / \mathrm{s}$ and the lowest flow velocity about $3.26 \mathrm{~m} / \mathrm{s}$. At the outermost side of the elbow, flow velocity decreases at first and then increases along the direction of fluid flow. In the straight section before the outlet of the elbow, flow velocity increases from the innermost side to the outermost side, with the highest flow velocity about $5.79 \mathrm{~m} / \mathrm{s}$ and the lowest flow velocity about $3.26 \mathrm{~m} / \mathrm{s}$. From the distribution of shear stress at the elbow (Figure 4(b)), the shear stress also decreases from the innermost wall to the outermost wall, with the largest shear stress about $80.7 \mathrm{~Pa}$ and the smallest shear stress about 34.0 Pa. At the outermost side of the elbow, the shear stress decreases at first and then increases along the direction of fluid flow. In the straight section before the inlet of the elbow, the distribution of shear stress is uniform about 55.2 Pa. Based on above analysis, a conclusion could be drawn that the higher flow velocity corresponds to the larger shear stress and the lower flow velocity corresponds to the smaller shear stress at the elbow. 


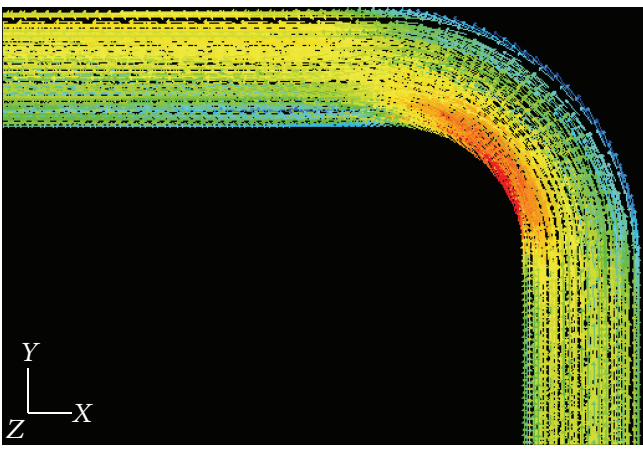

Velocity vectors colored by velocity magnitude $(\mathrm{m} / \mathrm{s})$ Fluent 6.2 (3d, segregated, ske)

(a)

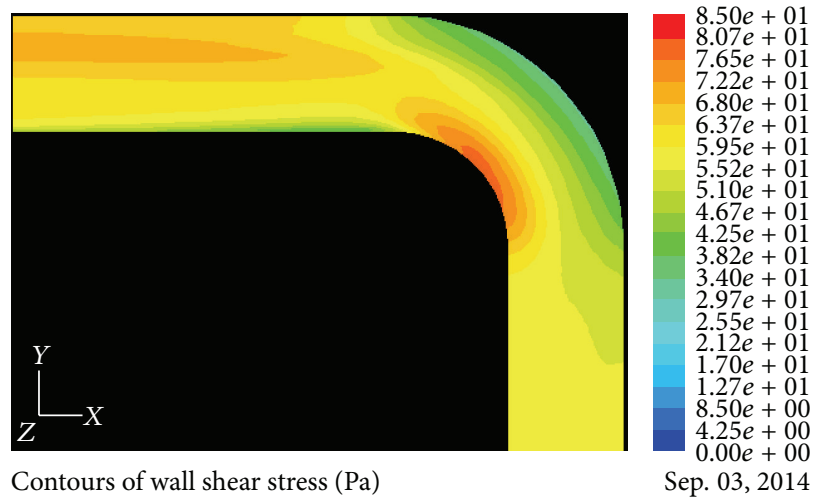

Fluent 6.2 (3d, segregated, ske)

(b)

Figure 4: The three-dimensional distributions of fluid flow velocity and shear stress at elbow with the flow velocity of $5.31 \mathrm{~m} / \mathrm{s}$ : (a) the distribution of fluid flow velocity and (b) the distribution of shear stress.
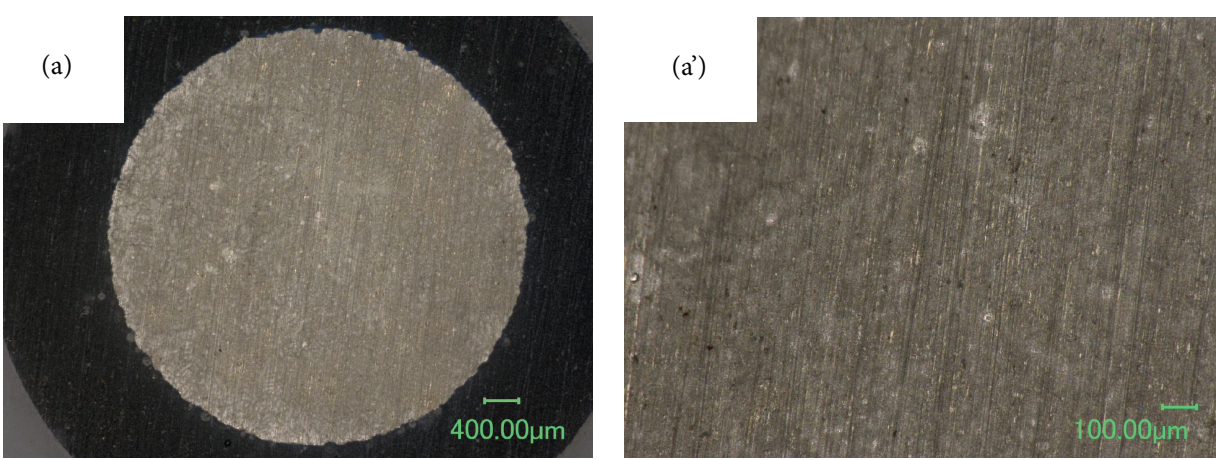

FIgURE 5: The surface morphologies of AZ91D after static state corrosion test for $4 \mathrm{~h}$.

3.3. Surface Morphology Analysis after FAC Test. Figure 5 shows the surface morphologies of the electrode after corrosion under static state condition for $4 \mathrm{~h}$. It is obviously seen from Figure 5 that there is a compact corrosion product film on the electrode surface. Figure 6 shows the surface morphologies of representative AZ91D magnesium alloy array electrodes after FAC test for $4 \mathrm{~h}$. It is seen from Figure 6 that there are obvious cutting tracks on the surface of these electrodes. Furthermore, the scale of the corrosion product films becomes more and more greater from the inside to the outside of the elbow. This can be explained that the removal of corrosion products on the electrode surface is easy with the high flow velocity and the large shear stress, but it is difficult for corrosion products to remove with the low flow velocity and the small shear stress.

\section{Discussion}

The corrosion of magnesium alloys in chloride-containing solution should include anodic dissolution of magnesium and cathodic hydrogen evolution [12], which can always be expressed as the following reaction:

$$
\begin{aligned}
& \mathrm{Mg} \longrightarrow \mathrm{Mg}^{+}+\mathrm{e}^{-} \text {or } \mathrm{Mg}^{+} \longrightarrow \mathrm{Mg}^{2+}+\mathrm{e}^{-} \\
& 2 \mathrm{H}_{2} \mathrm{O}+2 \mathrm{e}^{-} \longrightarrow 2 \mathrm{OH}^{-}+\mathrm{H}_{2} \text { or } 2 \mathrm{H}^{+}+2 \mathrm{e}^{-} \longrightarrow \mathrm{H}_{2}
\end{aligned}
$$

Although the corrosion mechanism of magnesium alloys may involve many complicated intermediate steps [5], the overall corrosion reaction can always be expressed as the following reaction:

$$
\mathrm{Mg}+2 \mathrm{H}_{2} \mathrm{O} \longrightarrow \mathrm{Mg}(\mathrm{OH})_{2}+\mathrm{H}_{2}
$$

Therefore, a corrosion product film consisting of $\mathrm{Mg}(\mathrm{OH})_{2}$ can be formed on magnesium alloy surface.

Potentiodynamic polarization measurement demonstrates that the electrochemical activity and corrosion behaviour of AZ91D magnesium alloy array electrodes are different at different locations of the elbow in circulating ASTM D1384-87 solution, as indicated in Figure 2. According 

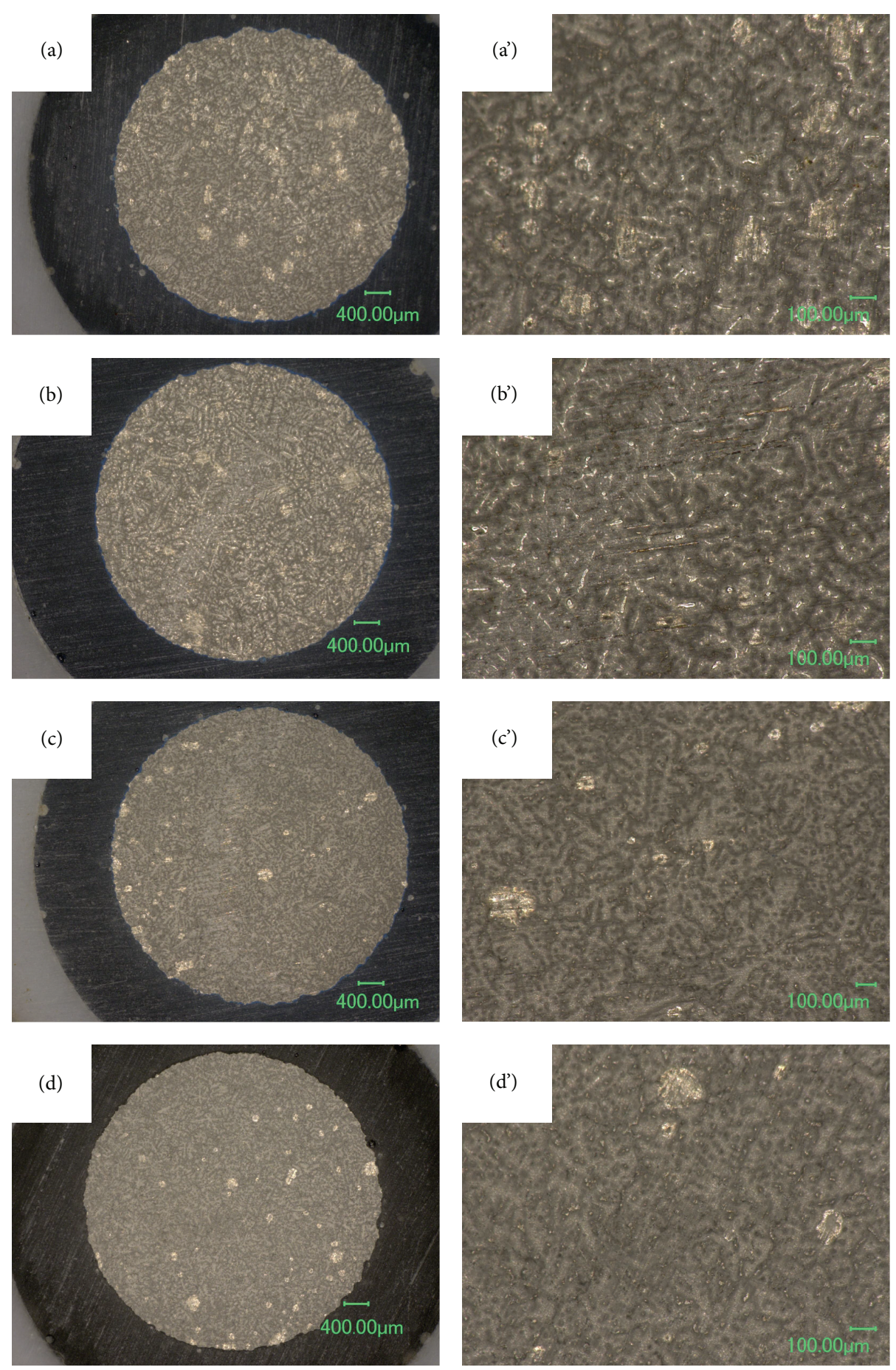

FiguRE 6: The surface morphologies of representative electrodes after FAC test for 4 h: (a) electrode 4, (b) electrode 10, (c) electrode 13, and (d) electrode 15 .

to Figure 2, AZ91D magnesium alloy is in an active dissolution state in the flowing solution, which can be attributed that fluid flow enhances the convection and diffusion of reactive species, accelerating the corrosion electrochemical reactions. Simultaneously, the severity of the erosive/abrasive attack to AZ91D magnesium alloy electrodes increases with increasing fluid flow velocity and shear stress, resulting in the more active electrode state and thus increasing corrosion rate of AZ91D magnesium alloy.

In this work, the CFD simulation indicates that there are quite different fluid flow velocities and shear stress at different locations along the elbow due to the geometrical change. The maximum corrosion rate appears at the innermost wall of the elbow with the maximum flow velocity and shear stress. 
The corrosion rate decreases from the innermost wall to the outermost wall of the elbow, with the higher corrosion rate corresponding to the higher flow velocity and the larger shear stress at the elbow. In the outermost wall of the elbow, the corrosion rate decreases at first and then increases along the direction of fluid flow, with the same variation for fluid flow velocity and shear stress. By comparing the CFD simulation results to the experimental results, it is demonstrated that fluid hydrodynamics plays a significant role in the FAC of AZ91D magnesium alloy. This can be explained by the fact that the velocity gradient near the wall and shear stress on the electrode surface are high under the high flow velocity condition. Then, the mass transfer rate is higher at the inner wall than that at the outer wall which is caused by the hydrodynamics change due to the geometrical configuration and orientation at the elbow [13]. Therefore, the comparison of electrochemical measurement with CFD simulation shows that a highly active AZ91D magnesium alloy electrode with a high dissolution rate is associated with a high flow velocity and a large shear stress at the elbow.

Additionally, the surface morphologies show that the scale of the corrosion product films at the inner wall is smaller than that at the outer wall at the elbow. At the inner wall, the removal of corrosion products on the electrode surface is easy due to the high flow velocity and the large shear stress, accompanied with the increase of corrosion rate, while the corrosion products are relatively difficult to remove at the outer wall due to the low flow velocity and the small shear stress, resulting in a relatively low corrosion rate. Apparently, fluid hydrodynamics plays a significant role in the FAC of AZ91D magnesium alloy.

\section{Conclusion}

Based on array electrode technology, FAC of AZ91D magnesium alloy at an elbow was investigated in loop system by potentiodynamic polarization, computational fluid dynamics simulation, and surface analysis. It is demonstrated that fluid hydrodynamics plays a significant role in the FAC of AZ91D magnesium alloy, and the distribution of the corrosion rates is in good accordance with the distributions of fluid flow velocity and shear stress at the elbow. The corrosion rate increases from the outer wall to the inner wall of the elbow, with the higher corrosion rate corresponding to the higher flow velocity and the larger shear stress at the elbow. In the outermost wall of the elbow, the corrosion rate decreases at first and then increases along the direction of fluid flow, with the same variation for fluid flow velocity and shear stress. The maximum corrosion rate appears at the innermost wall of the elbow, the location with the maximum flow velocity and shear stress.

\section{Conflict of Interests}

The authors declare that there is no conflict of interests regarding the publication of this paper.

\section{Acknowledgments}

The authors acknowledge the financial support of the National Natural Science Foundation of China (no. 51401151) and the Postdoctoral Science Foundation of China (no. 2012M511207). The authors also acknowledge the support of the Science Research Foundation of Wuhan Institute Technology (no. K201446).

\section{References}

[1] G. Song, A. L. Bowles, and D. H. St John, "Corrosion resistance of aged die cast magnesium alloy AZ91D," Materials Science and Engineering A, vol. 366, no. 2, pp. 74-86, 2004.

[2] T. Zhang, X. Liu, Y. Shao, G. Meng, and F. Wang, "Electrochemical noise analysis on the pit corrosion susceptibility of Mg-10Gd-2Y-0.5Zr, AZ91D alloy and pure magnesium using stochastic model," Corrosion Science, vol. 50, pp. 3500-3507, 2008.

[3] A. M. Fekry and M. Z. Fatayerji, "Electrochemical corrosion behavior of AZ91D alloy in ethylene glycol," Electrochimica Acta, vol. 54, no. 26, pp. 6522-6528, 2009.

[4] J. H. Nordlien, S. Ono, N. Masuko, and K. Nisancioglu, "Morphology and structure of oxide films formed on magnesium by exposure to air and water," Journal of the Electrochemical Society, vol. 142, no. 10, pp. 3320-3322, 1995.

[5] G. Song, A. Atrens, X. Wu, and B. Zhang, "Corrosion behaviour of AZ21, AZ501 and AZ91 in sodium chloride," Corrosion Science, vol. 40, no. 10, pp. 1769-1791, 1998.

[6] G. Baril, C. Blanc, and N. Pebere, "AC impedance spectroscopy in characterizing time-dependent corrosion of AZ91 and AM50 magnesium alloys characterization with respect to their microstructures," Journal of the Electrochemical Society, vol. 148, no. 12, pp. B489-B496, 2001.

[7] P. Schmutz, V. Guillaumin, R. S. Lillard, J. A. Lillard, and G. S. Frankel, "Influence of dichromate ions on corrosion processes on pure magnesium," Journal of the Electrochemical Society, vol. 150, no. 4, pp. B99-B110, 2003.

[8] N. LeBozec, M. Jönsson, and D. Thierry, "Atmospheric corrosion of magnesium alloys: influence of temperature, relative humidity, and chloride deposition," Corrosion, vol. 60, no. 4, pp. 356-361, 2004.

[9] J. Chen, J. Wang, E. Han, J. Dong, and W. Ke, "AC impedance spectroscopy study of the corrosion behavior of an AZ91 magnesium alloy in $0.1 \mathrm{M}$ sodium sulfate solution," Electrochimica Acta, vol. 52, no. 9, pp. 3299-3309, 2007.

[10] M. Ö. Öteyaka, E. Ghali, and R. Tremblay, "Corrosion behaviour of AZ and ZA magnesium alloys in alkaline chloride media," International Journal of Corrosion, vol. 2012, Article ID 452631, 10 pages, 2012.

[11] S. A. Salman, R. Ichino, and M. Okido, "A comparative electrochemical study of AZ31 and AZ91 magnesium alloy," International Journal of Corrosion, vol. 2010, Article ID 412129, 7 pages, 2010.

[12] G. L. Song and M. Liu, "The effect of surface pretreatment on the corrosion performance of Electroless E-coating coated AZ31," Corrosion Science, vol. 62, pp. 61-72, 2012.

[13] G. A. Zhang, L. Zeng, H. L. Huang, and X. P. Guo, "A study of flow accelerated corrosion at elbow of carbon steel pipeline by array electrode and computational fluid dynamics simulation," Corrosion Science, vol. 77, pp. 334-341, 2013. 
[14] W. S. Miller, L. Zhuang, J. Bottema et al., "Recent development in aluminium alloys for the automotive industry," Materials Science and Engineering A, vol. 280, no. 1, pp. 37-49, 2000.

[15] T. J. Harvey, J. A. Wharton, and R. J. K. Wood, "Development of synergy model for erosion-corrosion of carbon steel in a slurry pot," Tribology-Materials, Surfaces and Interfaces, vol. 1, no. 1, pp. 33-47, 2007.

[16] S. S. Rajahram, T. J. Harvey, and R. J. K. Wood, "Erosioncorrosion resistance of engineering materials in various test conditions," Wear, vol. 267, no. 1-4, pp. 244-254, 2009.

[17] S. S. Rajahramn, T. J. Harvey, and R. J. K. Wood, "Electrochemical investigation of erosion-corrosion using a slurry pot erosion tester," Tribology International, vol. 44, no. 3, pp. 232-240, 2011.

[18] D. López, N. Alonso Falleiros, and A. Paulo Tschiptschin, "Effect of nitrogen on the corrosionerosion synergism in an austenitic stainless steel," Tribology International, vol. 44, no. 5, pp. 610-616, 2011.

[19] R. C. Barik, J. A. Wharton, R. J. K. Wood, and K. R. Stokes, "Electro-mechanical interactions during erosion-corrosion," Wear, vol. 267, no. 11, pp. 1900-1908, 2009.

[20] M. M. Stack and N. Pungwiwat, "Particulate erosion-corrosion of $\mathrm{Al}$ in aqueous conditions: some perspectives on $\mathrm{pH}$ effects on the erosion-corrosion map," Tribology International, vol. 35, no. 10, pp. 651-660, 2002.

[21] G. T. Burstein and K. Sasaki, "Effect of impact angle on the slurry erosion-corrosion of 304L stainless steel," Wear, vol. 240, no. 1-2, pp. 80-94, 2000.

[22] A. Neville and C. Wang, "Erosion-corrosion mitigation by corrosion inhibitors-an assessment of mechanisms," Wear, vol. 267, no. 1-4, pp. 195-203, 2009.

[23] M. M. Stack and G. H. Abdulrahman, "Mapping erosioncorrosion of carbon steel in oil exploration conditions: some new approaches to characterizing mechanisms and synergies," Tribology International, vol. 43, no. 7, pp. 1268-1277, 2010.

[24] R. C. Barik, J. A. Wharton, R. J. K. Wood, K. S. Tan, and K. R. Stokes, "Erosion and erosion-corrosion performance of cast and thermally sprayed nickel-aluminium bronze," Wear, vol. 259, no. 1-6, pp. 230-242, 2005.

[25] R. Malka, S. Nešić, and D. A. Gulino, "Erosion-corrosion and synergistic effects in disturbed liquid-particle flow," Wear, vol. 262, no. 7-8, pp. 791-799, 2007.

[26] R. O. Rihan and S. Nesic, "Erosion-corrosion of mild steel in hot caustic. Part I: NaOH solution," Corrosion Science, vol. 48, no. 9, pp. 2633-2659, 2006.

[27] M. El-Gammal, H. Mazhar, J. S. Cotton, C. Shefski, J. Pietralik, and C. Y. Ching, "The hydrodynamic effects of single-phase flow on flow accelerated corrosion in a 90-degree elbow," Nuclear Engineering and Design, vol. 240, no. 6, pp. 1589-1598, 2010.

[28] J. Hu, D. Huang, G. Song, and X. Guo, "The synergistic inhibition effect of organic silicate and inorganic $\mathrm{Zn}$ salt on corrosion of Mg-10Gd-3Y magnesium alloy," Corrosion Science, vol. 53, no. 12, pp. 4093-4101, 2011. 

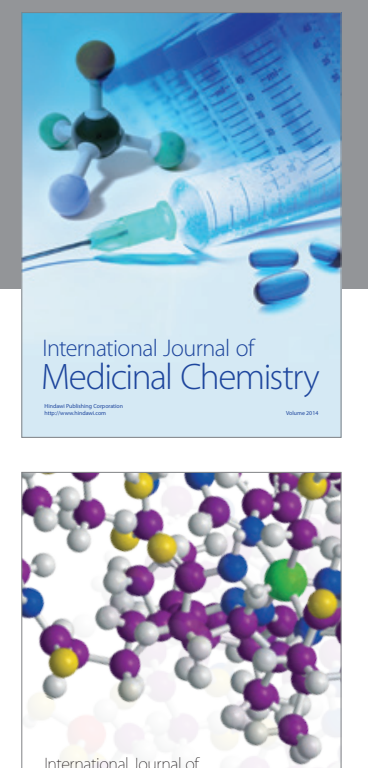

\section{Carbohydrate} Chemistry

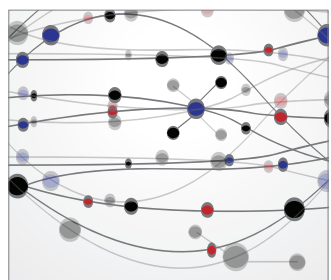

The Scientific World Journal
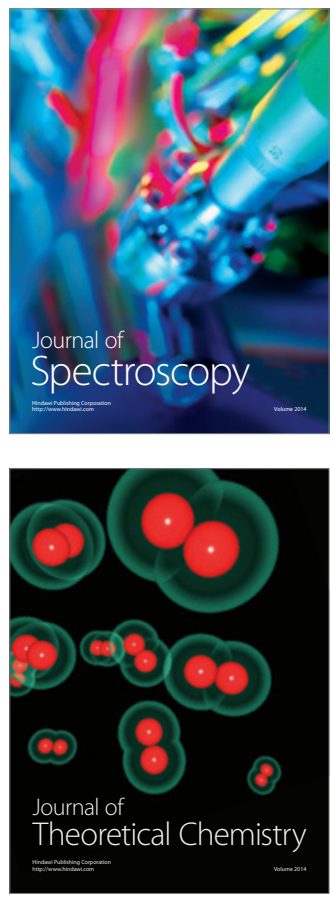


Submit your manuscripts at

http://www.hindawi.com

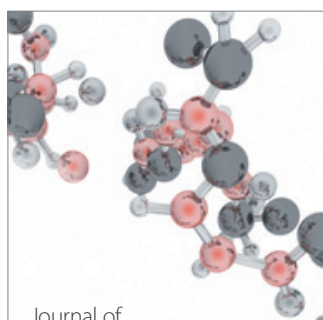

Analytical Methods

in Chemistry

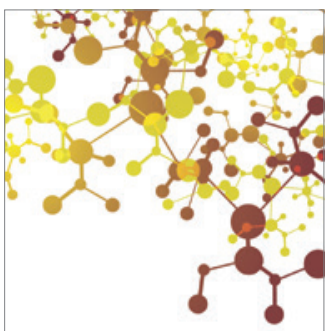

Journal of

Applied Chemistry

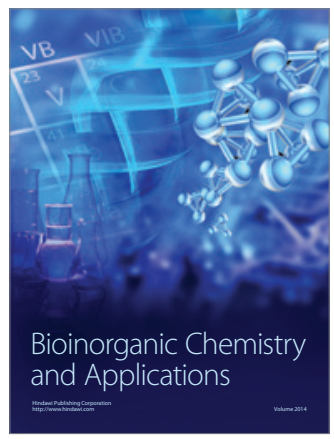

Inorganic Chemistry
